\title{
Cost Estimation of Electrokinetic Soil Remediation for Removal of Six Toxic Metals from Contaminated Soil
}

\author{
G. Koteswara Reddy †, V. Nikhil Reddy, V. Sunandini and K. Hemalatha \\ Department of Biotechnology, Koneru Lakshmaiah Education Foundation (Deemed to be University), Green Fields, \\ Vaddeswaram-522502, Guntur, Andhra Pradesh, India \\ †Corresponding author: G. Koteswara Reddy; koteswarareddy@kluniversity.in
}

Nat. Env. \& Poll. Tech.

Website: www.neptjournal.com

Received: 08-10-2020

Revised: $25-10-2020$

Accepted: $27-10-2020$

\section{Key Words:}

Toxic metals

Electrokinetics

Operating cost

Cost estimation models

\begin{abstract}
The purpose of the study is to estimate the operating cost of the electrokinetic methods in the removal of toxic metals (TMs) from granite mine tailing soil with the help of the proposed cost estimation models. The conventional electrokinetic technologies have not considered the cost estimation in the removal of TMs from polluted soils. In this study, we incorporated the chelates such as citric acid and ethylenediaminetetraacetic acid (EDTA) enhanced electrokinetic soil remediation process followed by a cost estimation of the processes. Our study proposed the cost estimation models to determine the operating cost of the conventional and enhanced electrokinetic treatment processes, specifically for the removal of six TMs such as chromium (Cr), cobalt (Co), copper (Cu), nickel (Ni), zinc ( $\mathrm{Zn}$ ) and manganese $(\mathrm{Mn})$ from granite mine tailing soil. We investigated the chelating enhanced electrokinetic removal of TMs about six times more than the conventional process for 20 days of operation. Furthermore, we estimated that the operating cost of the conventional and enhanced electrokinetic processes was about US $\$ 110$ to US $\$ 508$ per cubic meter of treated soil. The total operating cost was about US\$ 110 to US\$ 1006 per cubic meter of treated soil including enhancers cost. We believe the chelating enhanced electrokinetic treatment of soil was more effective than conventional treatment for removal of TMs from contaminated soil.
\end{abstract}

\section{INTRODUCTION}

Soil environment has been polluted by incorporation of toxic heavy metals and organic pollutants. Improper management and human activities cause soil contamination (Shukla \& Chandel 2005). Recent studies reported the toxic metals(TMs) such as chromium (Cr), cobalt (Co), nickel $(\mathrm{Ni})$, copper $(\mathrm{Cu})$, zinc $(\mathrm{Zn})$ and manganese $(\mathrm{Mn})$ at elevated concentrations in granite mining waste (Reddy \& Yarrakula 2019). During the mineral and milling process, a vast quantity of granite waste is produced and accumulated at dump yards, which may affect the environment (Santhosh et al. 2019). Recently, star-shaped microfluidic channel techniques have been used to detect the TMs (Satish et al. 2017). The concentrations of TMs assessed with advanced remote sensing technique and geography information technology system (GIS) particularly for groundwater (Asadi et al. 2017, Monica et al. 2018). The environmental impact assessment of TM polluted water and soil was determined to minimize environmental pollution (Koteswara \& Kiran 2019). Conventional methods such as biosorption, phytochemical oxidation, coconut coir, saxaul tree ash and nickel oxide/ carbon nanotube composites (NiO/CNT) investigated for the removal of TMs and organic pollutants from industrial waste disposal (Aravind et al. 2017, Pratapa et al. 2019). Most of the conventional remediation studies are ineffective and not feasible on a large scale at the field level. Electrochemical behaviour of different metals and metal alloys studied with sodium chloride solution for environmental applications (Suresh et al. 2018). The solubility of metals and TMs in the soil affected by the chemical composition of the soil as well as groundwater (Sposito 2008).

An electrokinetic soil remediation technology has emerged and successfully been applied for removal of TMs and organic contaminants from industrial wastewater and soil (FAO/WHO 2000). The removal of toxic TMs from clayey soil applied in several field applications by using electric current (Collins \& Kinsela 2011). Electrokinetic remediation is an advanced technique used in-situ and ex-situ removal of toxic metals, organic pollutants, and radio-nuclide materials from contaminated soil. Recent studies investigated the reducing agents enhanced electrokinetic remediation for removal of TMs from polluted soil (Reddy et al. 2019). The metal or TM ions would be desorbed under an acidic or low $\mathrm{pH}$ environment at the anode during the electrokinetic treatment (Sivapullaiah et al. 2015). Recently, many studies have focussed on zero waste/mitigation of waste/prevention 
of waste using reducing and chelating enhanced reagents in electrokinetic soil remediation technologies (Peng \& Tian 2010, Liu et al. 2017).

Conventional electrokinetic methods focussed on the removal of TMs from contaminated water and soil, but not considered the cost estimation of the process (Rosestolato et al. 2015). Several electrokinetic soil remediation studies not considered the cost estimation of the process however, each remediation step involved a cost in a real process (Gao et al. 2013, Reddy et al. 2019). We cope with this problem and proposed the operating cost estimation models soil remediation processes particularly in the electrokinetic removal TMs from mine tailing soils. Generally, an electrokinetic soil remediation process depends upon the treatment time (Ma et al. 2010), by means that longer treatment may also increase the operating cost of the process in terms of cost of chemical reagents and cost of the electrical energy (Pedersen et al. 2015). The basic idea of this study is to determine the operating cost of the electrokinetic treatment of contaminated soils particularly in the remediation of toxic metals. Our previous study investigated the removal of these six TMs using reducing agents enhanced electrokinetic soil remediation process (Reddy \& Yarrakula 2019). The TM ionic species would easily migrate from the soil surface to the electrolytic solutions in the presence of electric current (Giannis \& Gidarakos 2005, Giannis et al. 2009). Our previous study investigated the removal of these six TMs using reducing agents enhanced electrokinetic soil remediation process (Reddy et al. 2019). In this study, we incorporated the chelating agents (Citric acid and EDTA) for enhanced electrokinetic soil remediation process followed by the estimation of operating cost of the process.

The purpose of the study is to estimate the operating cost of the electrokinetic experiments for removal of TMs from granite mining soil with the help of proposed cost estimation models. The study is classified into two sections, the first section dealt with the electrokinetic removal of TMs by using most efficient chelating agents such as Citric acid and EDTA and subsequent section dealt with the estimation of the operating cost with help of proposed cost estimation models in this study.

\section{MATERIALS AND METHODS}

\section{Experimental Design}

Recent studies used the electrokinetic reactor with a design of $30 \mathrm{~cm} \times 20 \mathrm{~cm} \times 15 \mathrm{~cm}$ in laboratory scale and fabricated with Plexiglas along with two electrode chambers with dimensions of $5 \mathrm{~cm} \times 20 \mathrm{~cm} \times 15 \mathrm{~cm}$ and a working volume of 1.5L (Fig. 1) (Reddy et al. 2019). We used the same design of the electrokinetic reactor, and two graphite electrodes act as anode and cathode with a length of $15 \mathrm{~cm}$ and a diameter of $1.5 \mathrm{~cm}$. We conducted four different EKSR experiments with prior prepared anolyte and catholyte solutions as represented in Table 1.

\section{Determination of TMs Concentration and Electricity Consumption}

Atomic absorption spectroscopy (AAS) Varian AA110 spectrophotometer used to measure TMs concentration of the soil in pre-treatment and post-treatment of four electrokinetic experiments (Wang et al. 2014, Reddy et al. 2019). The removal efficiency or removal performance can be determined using the Equation (1) (Tang et al. 2014, Bahemmat et al. 2016).

$$
\text { Removal efficiency }(\%)=\frac{C_{0}-C_{f}}{C_{0}} \times 100
$$

Where, $C_{0}$ : Initial concentration, $C_{f}$ : Final concentration $(\mathrm{mg} / \mathrm{kg})$ of the soil pre-treatment and post-treatment of electrokinetic removal of TMs.

The expenditure of electrical energy is directly related to the remediation time using the integral time for the passing of current during the electrokinetic process across the electrokinetic reactor. The consumption of electricity to be determined with the Equation (2) (Ma et al. 2010, Pedersen et al. 2015).

Energy expenditure $\left(\mathrm{E}_{\mathrm{e}}\right)=P=\frac{1}{V_{S}} \int_{0}^{t} V I d t$

Where,

$\mathrm{E}_{\mathrm{e}}$ : The energy expenditure $\left(\mathrm{Wh} / \mathrm{m}^{3}\right)$,

P: The electrical power $(\mathrm{W})$

Table 1: Experimental pattern of four different EKSR experiments.

\begin{tabular}{|lllllll|}
\hline Exp. No. & Anolyte & Soil saturation & $\mathrm{pH}$ & Catholyte & Duration (Days) & Electric potential (V/cm) \\
\hline Exp.1 & Distilled water & Distilled water & 9.7 & Distilled water & $5,10,15,20$ & 2 \\
Exp.2 & Distilled water & $0.1 \mathrm{M}$ Citric acid & 5.7 & 0.1 M Citric acid & $5,10,15,20$ & 2 \\
Exp.3 & Distilled water & $0.1 \mathrm{M}$ Citric acid & 5.9 & $0.1 \mathrm{M} \mathrm{EDTA} *$ & $5,10,15,20$ & 2 \\
Exp.4 & $0.1 \mathrm{M} \mathrm{NaOH}$ & Distilled water & 9.7 & Distilled water & $5,10,15,20$ & 2 \\
\hline
\end{tabular}

* EDTA: Ethylenediaminetetraacetic acid 
$\mathrm{V}_{\mathrm{S}}$ : The volume of the soil $\left(\mathrm{m}^{3}\right)$

$\mathrm{I}$ : The current passage across the electrokinetic reactor (A)

$\mathrm{V}$ : The voltage $(\mathrm{V})$

$\mathrm{t}$ : The treatment time $(\mathrm{h})$

\section{Proposed Cost Estimation Models}

The operating cost of the electrokinetic experiments was estimated through the consumption of enhancing solutions and electrical energy during electrokinetic removal of TMs from mine tailing soil. The total cost of the process was estimated by adding the individual costs of enhancers and cost of electricity expenditure. Generally, the total cost of the electrokinetic process is directly related to the remediation time which includes the electricity supplied across the electrokinetic reactor. The cost of the enhancers was estimated by the quantity of enhancers consumed in the process multiplied by the cost of one unit. In the same way, the cost of electricity was estimated by the electricity consumption charges in India. Our study considered the operating cost of the electrokinetic experiments rather than the capital investment of the process.

Several studies used the equation (2) for estimating the amount of electricity consumed during electrokinetic removal of heavy metals from polluted soils (Ma et al. 2010, Pedersen et al. 2015, Reddy et al. 2019). We simplified the equation (2) into equations (4 and 5) for quick estimation of the cost of enhancers and the cost of the electricity for four different electrokinetic experiments. In this study, we proposed the following three cost estimation models to determine the enhancers cost, electricity cost and the total operating cost of the electrokinetic process. The models were well correlated with manual calculations in the estimation of enhancers cost and electricity cost for four different electrokinetic experiments.

Enhancers cost $\left(\mathrm{E}_{\mathrm{C}}\right)$ can be estimated by the following Equation (3):

$$
E_{C}=\frac{1}{V_{S}}\left[\sum_{i}^{n}\left(m_{i} \times c_{i}\right)\right]
$$

Electricity cost $\left(\mathrm{EE}_{\mathrm{C}}\right)$ can be estimated by the following Equation (4):

$$
E E_{C}=\frac{1}{V_{S}}\left[\left(10^{-3} \int_{0}^{t} V I d t\right) C_{c}\right]
$$

The Total cost $\left(\mathrm{T}_{\mathrm{C}}\right)$ can be estimated by the following Equation (5):

$$
T_{C}=\frac{1}{V_{S}}\left[\sum_{i}^{n}\left(m_{i} \times c_{i}\right)+\left(10^{-3} \int_{0}^{t} V I d t\right) C_{c}\right]
$$

Here,

$\mathrm{T}_{\mathrm{C}}$ : The total cost of the process including enhancers and energy cost

$\mathrm{V}_{\mathrm{S}}$ : The volume of the soil $\left(\mathrm{m}^{3}\right)$

$\mathrm{m}_{\mathrm{i}}$ : The amount of enhancing reagent $(\mathrm{kg})$

$\mathrm{C}_{\mathrm{i}}$ : The cost of enhancing reagent $(\$ / \mathrm{kg})$

I: The current passage across the electrokinetic reactor (A)

$\mathrm{V}$ : The voltage $(\mathrm{V})$

$\mathrm{t}$ : The treatment time (h)

\section{RESULTS AND DISCUSSION}

\section{Conventional Electrokinetic Experiment}

During the electrokinetic process, the toxic metal ionic species are dissociated from the soil surface and travelled between anode compartment and cathode compartment by electromigration, electrophoresis and electroosmosis. The metallic species was collected through anolyte and catholyte solutions and measured their concentration via acid digestion followed by atomic absorption spectrometry. A conventional electrokinetic experiment was performed for 5-20 days by purging distilled water for both the anode chamber and cathode chamber. Thereafter collected the anolyte and catholyte solution samples for detecting the TM species for every five days of treatment. The removal performance of TM species with respect to time was recorded and can be seen in the Experiment (1) (Fig. 1a). The removal percentage was about $6 \%, 9 \%, 16 \%, 24 \%, 11 \%$ and $32 \%$ respectively for $\mathrm{Cr}, \mathrm{Co}, \mathrm{Ni}, \mathrm{Cu}, \mathrm{Zn}$ and $\mathrm{Mn}$ after 20 days of treatment. The average percentage of removal of all metallic species found that around $13 \%$ by means that longer treatment time (>20days) is required to remove the TMs completely from mine tailing soil.

\section{Enhanced Electrokinetic Experiments}

During the enhanced electrokinetic process, the metallic species were collected through anolyte and catholyte solutions and measured their concentration via acid digestion followed by atomic absorption spectrometry. The enhanced electrokinetic experiments were performed for 5 to 20 days by purging citric acid and EDTA as chelates at the cathode chamber to suppress the increase in $\mathrm{pH}$ of catholyte. The acidic environment was most favoured for the dissociation 

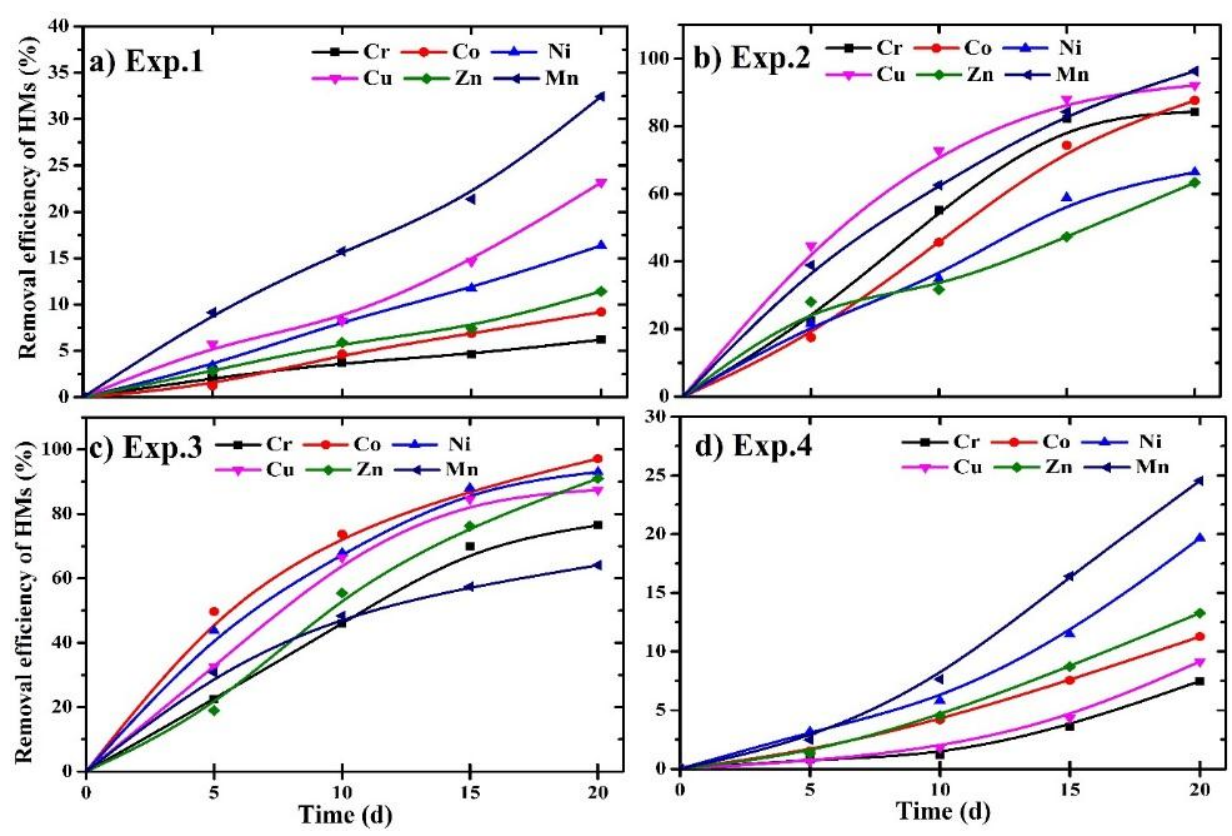

Fig. 1: Removal performance (\%) of TMs in experiments (1, 2, 3 and 4) w.r.t. time for 20 days.

of metallic species from the soil surface to anolyte/catholyte electrolyte solutions. Thereafter collected the anolyte and catholyte solution samples for detecting the TM species for every five days of treatment. The removal performance of TM species with respect to time was recorded (Fig. 1b \& 1c) and can be observed in Experiments $(2 \& 3)$. The removal percentage was ranged about $76 \%-84 \%, 88 \%-97 \%, 66 \%$ $93 \%, 87 \%-92 \%, 63 \%-91 \%$ and $64 \%-96 \%$ respectively for $\mathrm{Cr}, \mathrm{Co}, \mathrm{Ni}, \mathrm{Cu}, \mathrm{Zn}$ and $\mathrm{Mn}$ after 20 days of treatment. The average removal performance $(\%)$ of all metallic species found that around $84 \%$ by means that $25-30$ days treatment time is required to remove the TMs completely from mine tailing soil in the case of chelating enhanced electrokinetic experiments. However, the results demonstrated that the enhanced electrokinetic removal of TMs was about six times more than the conventional method.

\section{Alkali Electrokinetic Experiment}

The experiment (4) was performed for 5-20 days by purging sodium hydroxide $(\mathrm{NaOH})$ at the anode chamber to increase the $\mathrm{pH}$ of the anolyte solution. Thereafter collected the anolyte and catholyte solution samples for detecting the TM species for every five days of treatment. The removal performance of TM species with respect to time was recorded (Fig. 1d). The removal percentage was about $7 \%, 11 \%, 19 \%, 9 \%$, $13 \%$ and $24 \%$ respectively for $\mathrm{Cr}, \mathrm{Co}, \mathrm{Ni}, \mathrm{Cu}, \mathrm{Zn}$ and $\mathrm{Mn}$ after 20 days of treatment. The average percentage of removal of all metallic species found that around $14 \%$ by means that longer treatment time ( $>20$ days) is required to remove the TMs completely from mine tailing soil. The results indicated the removal of TMs in alkali electrokinetic experiment was close to conventional electrokinetic experiment.

\section{Cost Estimation of Electrokinetic Experiments}

In the case of the conventional electrokinetic experiment (1), the enhancers were not used, hence the total operating cost was directly related to the electricity consumption for 20 days of operation. The expenditure of electrical energy was about $1104 \mathrm{kWh} / \mathrm{m}^{3}$ respectively. However, the total operating cost estimated by the proposed model was around 110.4 US\$/ $\mathrm{m}^{3}$. The citric acid as enhancing electrokinetic experiment from Table 2 and Fig. 2, the total operating cost was directly related to the electricity consumption and the amount of citric acid utilized for 20 days of operation. The citric acid was consumed about $146 \mathrm{~kg} / \mathrm{m}^{3}$ with a cost of $293 \mathrm{US} \$ / \mathrm{m}^{3}$. The consumption of electricity was about $2480 \mathrm{kWh} / \mathrm{m}^{3}$ with a cost of $248 \mathrm{US} \$ / \mathrm{m}^{3}$ respectively. However, the total operating cost was estimated at around $541 \mathrm{US} \$ / \mathrm{m}^{3}$. In the case of EDTA, an enhancing electrokinetic experiment, the total cost was related to the electricity consumption and amount of citric acid consumed during removal of TMs for 20 days of operation. The consumption of EDTA was about $267 \mathrm{~kg} /$ $\mathrm{m}^{3}$ with a cost of $800 \mathrm{US} \$ / \mathrm{m}^{3}$ and citric acid cost was about $26 \mathrm{US} \$ / \mathrm{m}^{3}$ for soil saturation. The consumption of electricity 
was about $1800 \mathrm{kWh} / \mathrm{m}^{3}$ with a cost of $180 \mathrm{US} \$ / \mathrm{m}^{3}$ respectively. However, the total operating cost was estimated at around $1006 \mathrm{US} \$ / \mathrm{m}^{3}$. In the case of the alkali electrokinetic experiment, the total operating cost was directly related to the electricity consumption and amount of $\mathrm{NaOH}$ utilized for 20 days of operation. The $\mathrm{NaOH}$ was consumed about $53.3 \mathrm{~kg} / \mathrm{m}^{3}$ with a cost of $112 \mathrm{US} \$ / \mathrm{m}^{3}$. The consumption of electricity was about $5080 \mathrm{kWh} / \mathrm{m}^{3}$ with a cost of 508US\$/ $\mathrm{m}^{3}$ respectively. However, the total operating cost was estimated around $620 \mathrm{US} \$ / \mathrm{m}^{3}$ (Fig. 2). The electricity cost of experiment 4 with $\mathrm{NaOH}$ was almost twice higher than other experiments 1-3, it might be the reason that the increase in $\mathrm{pH}$ of the soil matrix during the electrokinetic process.

The results demonstrated that conventional and alkali electrokinetic experiments were costly and not effective in the removal of TMs from contaminated soils. The citric acid enhanced electrokinetic experiment was more effective and economically feasible than the EDTA enhanced electrokinetic experiment in the removal of TMs from contaminated soils.

\section{CONCLUSION}

Our study proposed the cost estimation models to estimate the operating cost such as cost of chemical reagents, cost of electrical energy and total cost of the process in the electrokinetic removal of TMs from contaminated soil. We estimated the operating cost of conventional and enhanced electrokinetic treatment processes in specifically for the removal of six TMs such as chromium $(\mathrm{Cr})$, cobalt $(\mathrm{Co})$, copper $(\mathrm{Cu})$, nickel $(\mathrm{Ni})$, zinc $(\mathrm{Zn})$ and manganese $(\mathrm{Mn})$ from granite mine tailing soil. We investigated that the chelating enhanced electrokinetic removal of TMs about six times more than the conventional process in 20 days of operation. Furthermore, we estimated the operating cost of the conventional and enhanced electrokinetic processes was about US\$110 to US $\$ 508$ per cubic meter of treated soil. The total operating cost becomes US\$110 to US\$1006 per cubic meter of treated soil including enhancers cost. We conclude that the chelating enhanced electrokinetic treatment of soil was more effective and economically feasible than conventional treatment for removal of TMs from contaminated soil.

Table 2: Cost estimation of four electrokinetic experiments.

\begin{tabular}{|c|c|c|c|c|c|c|c|c|c|}
\hline \multirow{3}{*}{$\begin{array}{l}\text { Exp. } \\
\text { No }\end{array}$} & \multicolumn{6}{|c|}{ Enhanced solution consumption } & \multirow{2}{*}{\multicolumn{2}{|c|}{$\begin{array}{l}\text { Energy consumption } \\
\text { Power }\end{array}$}} & \multirow{3}{*}{$\begin{array}{l}{ }^{\mathrm{e}} \text { Total cost } \\
\left(\$ / \mathrm{m}^{3}\right)\end{array}$} \\
\hline & \multicolumn{2}{|l|}{ Citric acid } & \multicolumn{2}{|l|}{ EDTA } & \multicolumn{2}{|l|}{$\mathrm{NaOH}$} & & & \\
\hline & $\begin{array}{l}\text { Consumption } \\
\left(\mathrm{kg} / \mathrm{m}^{3}\right)\end{array}$ & $\begin{array}{l}{ }^{\mathrm{a}} \text { Cost } \\
(\$)\end{array}$ & $\begin{array}{l}\text { Consumption } \\
\left(\mathrm{kg} / \mathrm{m}^{3}\right)\end{array}$ & $\begin{array}{l}{ }^{\mathrm{b}} \text { Cost } \\
(\$)\end{array}$ & $\begin{array}{l}\text { Consump- } \\
\text { tion }\left(\mathrm{kg} / \mathrm{m}^{3}\right)\end{array}$ & $\begin{array}{l}{ }^{\mathrm{c}} \text { Cost } \\
(\$)\end{array}$ & $\begin{array}{l}\text { Consumption } \\
\left(\mathrm{kwh} / \mathrm{m}^{3}\right)\end{array}$ & $\begin{array}{l}{ }^{\mathrm{d}} \text { Cost } \\
(\$)\end{array}$ & \\
\hline Exp.1 & 0 & 0 & 0 & 0 & 0 & 0 & 1104 & 110.4 & 110.4 \\
\hline Exp. 2 & 146.6 & 293.2 & 0 & 0 & 0 & 0 & 2480 & 248 & 541.2 \\
\hline Exp.3 & 13.3 & 26.6 & 266.6 & 800 & 0 & 0 & 1800 & 180 & 1006.6 \\
\hline Exp.4 & 0 & 0 & 0 & 0 & 53.33 & 112 & 5080 & 508 & 620 \\
\hline
\end{tabular}

${ }^{\mathrm{a}}$ Cost of citric acid per kg: $2 \$ ;{ }^{\mathrm{b}}$ Cost of EDTA per kg: $3 \$ ;{ }^{\mathrm{c}}$ Cost of $\mathrm{NaOH}$ pellets per $\mathrm{kg}: 2.1 \$ ;{ }^{\mathrm{d}}$ Average cost of electricity consumption in India per kilo-Watt-hour(kWh): $0.1 \$$.

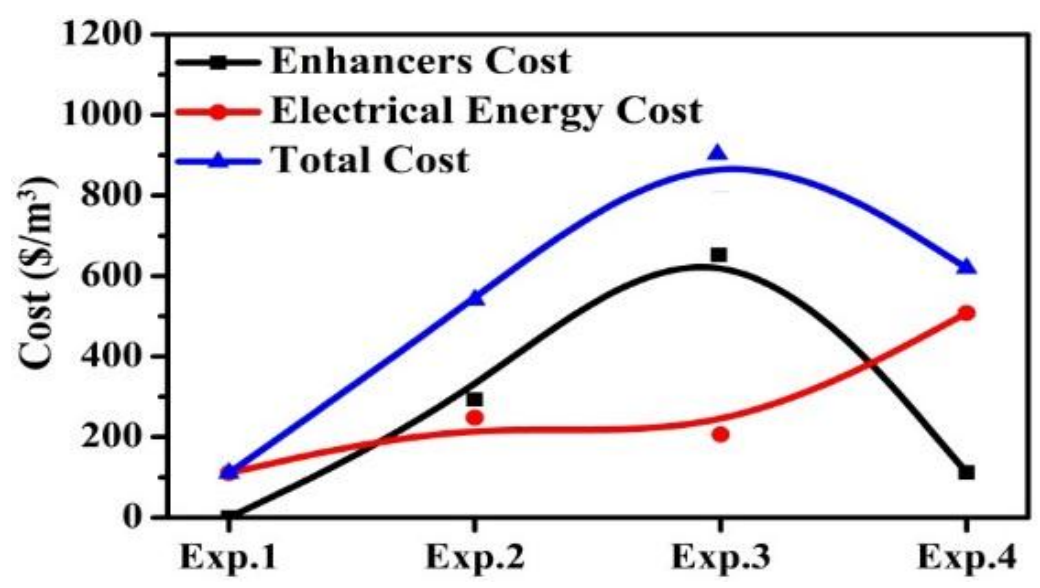

Fig. 2: Cost Estimation of four electrokinetic experiments. 


\section{REFERENCES}

Aravind, C., Chanakya, K. and Mahindra, K. 2017. Removal of heavy metals from industrial waste water using coconut coir. Int. J. Civ. Eng. Technol., 8: 1869-1871.

Asadi, S.S., Lahari, K. and Sai Madhulika, K. 2017. Analysis of soil quality for environmental impact assessment -a model study. Int. J. Civ. Eng. Technol., 8: 798-805.

Bahemmat, M., Farahbakhsh, M. and Kianirad, M. 2016. Humic substancesenhanced electroremediation of heavy metals contaminated soil. J. Hazard. Mater., 312: 307-318.

Collins, R.N. and Kinsela, A.S. 2011. Pedogenic factors and measurements of the plant uptake of cobalt. Plant Soil., 339: 499-512.

FAO/WHO 2000. Health risk of heavy metals from long-range transboundary air pollution. Europe Guidelines.

Gao, J., Luo, Q. and Zhang, C. 2013. Enhanced electrokinetic removal of cadmium from sludge using a coupled catholyte circulation system with multilayer of anion exchange resin. Chem. Eng. J., 234: 1-8.

Giannis, A. and Gidarakos, E. 2005. Washing enhanced electrokinetic remediation for removal cadmium from real contaminated soil. J. Hazard. Mater., 123: 165-175.

Giannis, A., Nikolaou, A., Pentari, D. and Gidarakos, E. 2009. Chelating agent-assisted electrokinetic removal of cadmium, lead and copper from contaminated soils. Environ. Pollut., 157: 3379-3386.

Koteswara, Reddy. G. and Kiran, Y. 2019. A theoretical mechanism in the degradation of polyolefin plastic waste using phytochemical oxidation process. J. Solid. Waste Technol. Manag., 45: 468-477.

Liu, Y., Chen, J. and Cai, Z. 2017. Removal of copper and nickel from municipal sludge using an improved electrokinetic process. Chem. Eng. J., 307: 1008-1016.

Ma, J.W., Wang, F.Y., Huang, Z.H. and Wang, H. 2010. Simultaneous removal of 2,4-dichlorophenol and $\mathrm{Cd}$ from soils by electrokinetic remediation combined with activated bamboo charcoal. J. Hazard. Mater., 176: 715-720.

Monica, C.L., Raju, M.V. and Kumar, D.V. 2018. Assessment of heavy metal concentrations and suitability study of ground water (bore wells) quality for construction purpose: A model study. Int. J. Civ. Eng. Technol., 9: 1273-1282.

Pazos, M., Plaza, A., Martín, M. and Lobo, M.C. 2012. The impact of electrokinetic treatment on a loamy-sand soil properties. Chem. Eng. J., 183: 231-237.

Pedersen, K.B., Kirkelund, G.M. and Ottosen, L.M. 2015. Multivariate methods for evaluating the efficiency of electrodialytic removal of heavy metals from polluted harbour sediments. J. Hazard. Mater., 283: 712-720.

Peng, G. and Tian, G. 2010. Using electrode electrolytes to enhance electrokinetic removal of heavy metals from electroplating sludge. Chem. Eng. J., 165: 388-394.

Pratapa, Reddy. Y., Narayana, K.L. and Kedar, Mallik M. 2019. Electrochemical behaviour of different metals in sodium chloride solution. Int. J. Emerg. Trends Eng. Res., 7: 715-719.

Reddy, G.K., Yarrakula, K. and Lakshmi, U.V. 2019. Reducing agents enhanced electrokinetic soil remediation (EKSR) for heavy metal contaminated soil. Iran. J. Chem. Chem. Eng., 38: 183-199.

Reddy, G.K. and Yarrakula, K. 2019. Geo-chemical exploration of granite mining waste using XRD, SEM/EDX and AAS analysis. Iran. J. Chem. Chem. Eng., 38: 215-228.

Reddy, K.R. 2013. Electrokinetic remediation of soils at complex contaminated sites. Coupled Phenom Environ. Geotech., 131-147.

Rosestolato, D., Bagatin, R. and Ferro, S. 2015. Electrokinetic remediation of soils polluted by heavy metals (mercury in particular). Chem. Eng. J., 264: 16-23.

Santhosh, C., Kishore, K.H. and Lakshmi, G.P. 2019. A detection of heavy metal ions using star-shaped microfluidic channel. Int. Emerg. Trends in Engg. Res.,7: 768-771.

Satish, Kumar.M., Asadi, S.S. and Vutukuru, S.S. 2017. Assessment of heavy metal concentration in ground water by using remote sensing and GIS. Int. J. Civ. Eng. Technol., 8: 1562-1573.

Shukla, R.S. and Chandel, P.S. 2005. A Textbook of Plant Ecology. S. Chand and Company LTD, 10th Edition.

Sivapullaiah, P.V., Nagendra Prakash, B.S. and Suma, B.N. 2015. Electrokinetic removal of heavy metals from soil. J. Electrochem. Sci. Eng., 5: 47-65.

Sposito, G. 2008. Chemistry of Soils. Oxford University Press, 2nd Edition, New-York.

Suresh, G., Narayana, K.L. and Mallik, M.K. 2018. Electrochemical behaviour of lens TM deposited Co-Cr-W alloy for bio-medical applications. Int. J. Mech. Prod. Eng. Res. Dev., 2018: 41-52.

Tang, W.W., Zeng, G.M. and Gong, J.L. 2014. Impact of humic/fulvic acid on the removal of heavy metals from aqueous solutions using nanomaterials: A review. Sci. Total Environ., 468-469: 1014-1027.

Traina, G., Morselli, L. and Adorno, G.P. 2007. Electrokinetic remediation of bottom ash from municipal solid waste incinerator. Electrochim. Acta., 52: 3380-3385

Wang, Y., Fang, Z., Liang, B. and Tsang, E.P. 2014. Remediation of hexavalent chromium contaminated soil by stabilized nanoscale zero-valent iron prepared from steel pickling waste liquor. Chem. Eng. J., 247: 283-290. 